
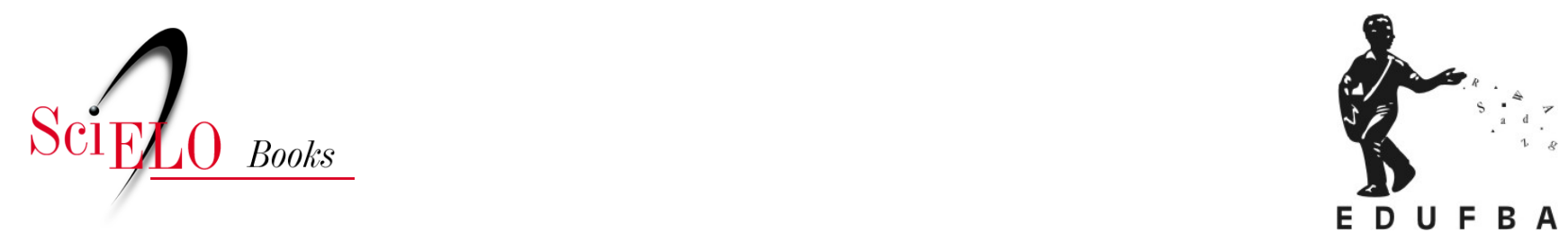

\title{
Balbina de Jesus \\ um estudo de caso sobre a organização do trabalho informal de feirante - concepção, execução e cuidado de si
}

\author{
Saulo Robledo Cardoso \\ Maria do Carmo Soares de Freitas \\ Rita de Cássia Pereira Fernandes
}

\section{SciELO Books / SciELO Livros / SciELO Libros}

CARDOSO, S.R., FREITAS, M.C.S., and FERNANDES, R.C.P. Balbina de Jesus: um estudo de caso sobre a organização do trabalho informal de feirante - concepção, execução e cuidado de si. In: LIMA, M.A.G., FREITAS, M.C.S., PENA, P.G.L., and TRAD, S., orgs. Estudos de saúde, ambiente e trabalho: aspectos socioculturais [online]. Salvador: EDUFBA, 2017, pp. 125-144. ISBN: 978-85232-1864-5. http://doi.org/10.7476/9788523218645.0007

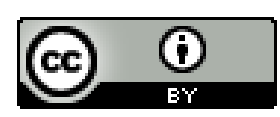

All the contents of this work, except where otherwise noted, is licensed under a Creative Commons Attribution $\underline{4.0 \text { International license. }}$

Todo o conteúdo deste trabalho, exceto quando houver ressalva, é publicado sob a licença $\underline{\text { Creative Commons }}$ Atribição 4.0. 


\title{
Balbina de Jesus
}

\section{um estudo de caso sobre a organização do trabalho informal de feirante - concepção, execução e cuidado de si}

\author{
SAULO ROBLEDO CARDOSO \\ MARIA DO CARMO SOARES DE FREITAS \\ RITA DE CÁSSIA PEREIRA FERNANDES
}

\section{Introdução}

\begin{abstract}
Antes de vir pra feira eu morava no interior, trabalhava na cozinha "do branco" (com menos de 12 anos), depois descobri que tinha uma irmã em Salvador, vim procurar ela. Fiquei com ela [...]. O marido dela querendo me seduzir, eu larguei ela e fui trabalhar com um "coroa" que tinha idade de ser meu pai. Muita "cantiga” e eu acabei "caindo", eu tinha quatorze anos. Eu na minha inocência, tabaroa, chegada do interior sem experiência, caí naquele conto. A primeira coisa que me apareceu foi uma filha. Tenho uma filha de 43 anos. (Balbina)
\end{abstract}

Este estudo apresenta as condições de vida e trabalho de uma feirante, moedora da raiz de mandioca na Feira de São Joaquim, cidade do Salvador, Bahia. Antes de contar sobre sua vida e seu trabalho, faz-se um breve comentário histórico sobre a concepção de feira enquanto lugar de comercializar alimentos e outros objetos da vida cotidiana. 
Surgiram as feiras na Europa do século IX com o objetivo de suprir as populações dos aglomerados urbanos, de gêneros de primeira necessidade (PIRENNE, 1936), constituindo-se como um espaço onde:

Agregavam-se pequenos comerciantes, mercadores diversos, camponeses, artífices, mendigos, simples transeuntes, que ocupavam o espaço público, geralmente no centro das cidades ou nos seus bairros mais movimentados que muitas vezes se confundiam com a formação das próprias cidades. (PENA; THÉBAUD-MONY, 1995, p. 74)

A importância sociocultural e econômica desses espaços, ao longo do tempo, está na constituição de inúmeras atividades de trabalho. E para apreensão deste tipo de patrimônio social e humano é necessário estabelecer uma visão sistemática e crítica sobre o feirante e suas atividades, considerando as dimensões físicas, cognitivas e psíquicas do trabalho que refletem na saúde desses trabalhadores. Nesse sentido, é objetivo deste artigo apresentar o trabalho de ralação de mandioca a partir das concepções de uma feirante, Balbina de Jesus, há mais de 30 anos atuando na Feira de São Joaquim (FSJ), e a partir daí, refletir sobre a saúde dos feirantes.

Especificamente, descreve-se cuidadosamente um tipo de atividade que demanda mais de dez horas por dia, um exercício físico e mental do trabalhador, que resulta num esforço intenso dos braços, postura e atenção permanente sobre o funcionamento de uma máquina raladora de mandioca. Esta atividade é exercida há mais de seis anos por Balbina, criadora desta ferramenta artesanal utilizada cotidianamente.

\section{Metodologia}

A atividade de ralar mandioca desenvolvida por Balbina no ambiente da FSJ constitui o foco principal dos resultados apresentados aqui. Neste estudo de caso, a observação participante, os registros de campo, as entrevistas, tendo como referência a abordagem da Análise Ergonômica do Trabalho (AET), que permitiram inclusive a aproximação com a história de vida dessa trabalhadora, compõem o conjunto de ferramentas e a base metodológica e instrumental do desenvolvimento dessa pesquisa.

O contato com a teoria compreensiva, desenvolvida por Geertz (1989), com os estudos de Freitas, Minayo e Fontes (2011) e Minayo (2008), e com 
obras como A arte de contar e trocar experiências, de Souza (2006), e Memória e sociedade: lembranças de velhos, de Bosi (1994) contribuiram significativamente para o alcance dos objetivos deste estudo.

Destaca-se a importância da Análise Ergonômica do Trabalho (AET), que corroborou um exame detalhado dos processos organizacionais e relacionais, além de possibilitar uma melhor apreensão do contexto estudado, visando contribuir para o desenvolvimento do campo da saúde do trabalhador feirante e informal. Para esta abordagem metodológica, o estudo se apoia em autores como: Guérin e colaboradores (2001), Schwartz e Durrive (2007), Clot ([201-]), entre outros.

Schwartz (1999) propõe um modelo de compreensão do trabalho considerando três polos de análise. $\mathrm{O}$ primeiro comporta distintos materiais para o conhecimento do feirante, tais como, a distinção entre trabalho prescrito e real, que no ambiente da feira possui uma construção diferenciada do mercado de trabalho formal; a noção de mercado diante das limitações de escolarização; o corpo humano e o cuidado com o trabalho; práticas linguísticas e dificuldades de comunicação, pois nem sempre há palavras em suficiência para expressar os argumentos. O segundo diz respeito aos saberes gerados nas atividades: a experiência. $\mathrm{O}$ terceiro é a aprendizagem proporcionada no convívio com o outro, o semelhante. Na FSJ, observa-se fenômenos correspondentes aos mencionados por este autor, como será demonstrado no desenvolver deste trabalho.

Guérin e colaboradores (2001) trazem os conceitos centrais de tarefa e atividade ou trabalho real, que se basearam no estudo do trabalho feirante, e, em particular, o trabalho de Balbina. Nesta perspectiva da AET, a atividade se conforma em situação de trabalho e é entendida como o modo pelo qual o trabalhador se relaciona com os objetivos e com os meios disponíveis para realizar as tarefas. Neste contexto, ele se move, gesticula, olha, escuta, se comunica; organiza seu trabalho, planifica suas ações, raciocina, toma decisões, controla os resultados; além de colocar em ação suas funções fisiológicas e mentais.

Outra noção relevante da abordagem ergonômica do trabalho é a de variabilidade. $\mathrm{O}$ entendimento de que não há situação permanentemente estável de trabalho é fundante desta abordagem metodológica. Os sujeitos que trabalham são diversos - variabilidade inter e intraindividual, bem como as condições em que o trabalho é desenvolvido - variabilidade de 
processo ou de sistema de trabalho, variabilidade de materiais e de equipamentos. Para lidar com essa variabilidade, ou com as perturbações, que podem ser apreendidas como características estruturais do sistema de trabalho, os trabalhadores modificam os objetivos ou os meios disponíveis para assegurar a conclusão das tarefas, a qualidade do realizado, e ainda para minimizar os riscos à saúde. No entanto, essas regulações, ou estratégias adotadas individualmente ou coletivamente pelos trabalhadores, nem sempre são possíveis em situações de trabalho muito restritivas, em que a precariedade dos meios impõe a realização das tarefas sob estado de fadiga física e psíquica. Nessas circunstâncias, o adoecimento do trabalhador não é evento imprevisto e pode resultar de uma inter-relação complexa entre diversos fatores do trabalho e da regulação possivelmente adotada pelo trabalhador. (GUÉRIN et al., 2001)

Esses conceitos e noções para análise do trabalho nortearam os caminhos metodológicos do presente estudo.

Durante oito meses foram realizadas observações, registros, e uma série de entrevistas em profundidade com Balbina e outros trabalhadores que compartilham da atividade de ralar mandioca. Contudo, elegeu-se esta mulher como entrevistada principal para uma descrição mais densa desse fenômeno, por perceber em seus discursos significados mais contundentes sobre o contexto e seu trabalho. Para a análise minudente da sua ocupação, foi fundamental a aproximação com os fragmentos da sua história de vida, sobretudo a vida laboral. A partir da observação e do registro de imagens do cotidiano, constatou-se o esforço físico e mental empreendido por esta mulher e os passos que organizam sua atividade na máquina raladora de mandioca.

\section{Feira de São Joaquim - FSJ}

Antes mesmo de descrever a atividade de ralação da mandioca por Balbina, considera-se necessário apresentar a feira e a organização do trabalho feirante, em que se destacam saberes e outros dilemas de ordem política, social, legal e econômica, além do pertencimento à informalidade. Também, destaca-se a análise da atividade feirante com seu processo de desenvolvimento e as influências culturais.

A Feira de São Joaquim nasce na década de 1920, com o nome de Feira do Sete, por ocupar a frente do sétimo galpão da Companhia das Docas do 
Estado da Bahia (CODEBA), na qual se iniciou o processo de relação conturbada com os poderes públicos, inaugurado com o primeiro deslocamento desta feira para um local denominado de Bacia de Água de Meninos.

Entretanto, foram apontadas questões de saúde e segurança como razões para o poder público tentar extinguir as atividades dessa feira. Em setembro de 1964, ocorreu a maior investida atribuída pelos feirantes aos militares golpistas para a sua total extinção: a feira foi tragicamente vitimada por dois incêndios seguidos, que a destruíram completamente, conforme relatos dos antigos trabalhadores.

É nesse momento de conflito que ocorre o mais representativo enfrentamento entre o sindicato organizado pela união dos feirantes, - para a garantia dos direitos ao exercício de suas atividades - e o poder público. Os feirantes, através das suas lideranças sindicais, reivindicavam um novo espaço para a continuidade das suas atividades. Nesse mesmo ano (1964), o Governo do Estado concede o direito de uso de um terreno da União, na enseada de São Joaquim, a aproximadamente 300 metros da antiga feira. A concessão dada em caráter provisório teria a duração de 31 anos. Mas, na prática, a FSJ se estabeleceu, configurando-se como uma conquista efetiva dos feirantes. Segundo relato dos feirantes, em todo esse tempo, não houve qualquer auxílio do Estado. Passados mais de 40 anos, o governo finalmente apresenta um projeto de requalificação para a Feira de São Joaquim.

Souza (2010, p. 225), em seu estudo sociológico sobre as teias que envolvem a sobrevivência da Feira de São Joaquim, identifica que:

As formações sociais sempre têm a percepção da possibilidade de seu desaparecimento, identificado como o caos e a desordem. Em contextos de crise, ou ante ameaças, suas forças se mobilizam no sentido de impulsionar modos de recriação e renovação, flexibilização, barganhando ou negociando - como estratégias de sobrevivência.

Nesse sentido, entende-se que as atividades desses feirantes têm como referência duas grandes situações: a necessidade de reconstrução de antigas e precárias instalações e, por outro lado, dar conta do seu desenvolvimento humano para a superação das dificuldades econômicas, sociais e ocupacionais vivenciadas. 
Para a análise do atual estado da FSJ, apresentam-se dados contextuais acerca deste peculiar local de comercialização. Vale ressaltar que atualmente, com uma estrutura de $36.595 \mathrm{~m}^{2}$ e 3065 feirantes cadastrados, divididos entre 2165 em boxes e 906 em bancas, esta é a maior feira da cidade do Salvador. Recebe um público diário estimado em mais de 10.000 pessoas, entre compradores e visitantes (BAHIA, 2008), e, conforme relatos de representantes do Sindicato do Comércio Varejista de Feirantes e Ambulantes da Cidade do Salvador (Sindifeira), há ainda centenas de trabalhadores não cadastrados.

Em vias da conclusão do seu processo de tombamento, a FSJ é considerada berço de inúmeras manifestações culturais, de expressões artísticas, comidas típicas e produtos diversos. Representando o principal centro de comercialização do artesanato produzido no Recôncavo Baiano, além de animais vivos, hortifrutigranjeiros e artigos utilizados nos rituais das religiões de matriz africana da cidade de Salvador.

Entretanto, ao considerar os aspectos sanitários, observam-se valores da cultura que parecem negligenciar a saúde ambiental conforme os ditames da vigilância sanitária. Tudo parece sujo, feio e de mau cheiro. Veem-se restos de pescados, vísceras expostas, moscas sobre os alimentos etc. No chão, quase sempre enlameado, encontram-se verduras, legumes, animais vivos e abatidos. Em meio às atividades comerciais estão crianças (filhos e netos dos comerciantes), cachorros, gatos, ratos e o lixo que se acumula inevitavelmente no cenário feirante. Observa-se precárias condições no acondicionamento e na manipulação das mercadorias, numa clara demonstração de insegurança alimentar. Nem sempre há sanitários, quase sempre são adaptações nos fundos das pequenas barracas.

Essas e outras observações sobre riscos de contaminação ambiental e para a saúde dos trabalhadores e consumidores da feira confirmaram a necessidade de um novo modus operandi, capaz de apresentar melhorias efetivas no ambiente. Diante da ameaça de fechamento da feira por insalubridade pelo Ministério Público Estadual, o Governo do Estado apresentou como solução para o quadro acima relatado, o Projeto de Requalificação da Feira de São Joaquim (PRFSJ), em execução pela Secretaria Estadual do Turismo.

A intervenção do poder público na FSJ iniciou-se no ano de 2012, e trouxe à tona a discussão junto ao Sindifeira, sobre a necessidade de uma aproximação real das situações de trabalho peculiares nesse espaço. 
Entretanto, diante de um ambiente polifônico e polissêmico desse universo, com múltiplas funções de trabalho, é perceptível no projeto de requalificação da FSJ a ausência de uma análise segmentada, com vistas a proporcionar a compreensão e o desenvolvimento particular e coletivo desse lugar-feira.

A relevância do desenvolvimento de iniciativas voltadas à preservação de feiras livres diz respeito não apenas a questões socioeconômicas, mas, sobretudo, aos processos que envolvem a cultura de mercados públicos. Neste contexto, Pena e Thébaud-Mony (1995) chamam a atenção para a significância histórica da feira popular, onde se dá a circulação dos consumidores, $\mathrm{o}$ aspecto econômico de compras a baixo preço, as relações sociais de proximidade e a permanência de valores culturais e afetivos.

Do mesmo modo, a eficiência de projetos desta ordem depende das conexões entre o planejamento oficial e as reais necessidades dos beneficiários. Para valorizar a experiência desses trabalhadores feirantes, é preciso observar as diversas atividades consonantes a esse tipo de comércio, entendendo sua historicidade, a cultura e as estratégias de sobrevivência para a produção e venda de mercadorias, na sua grande maioria, processadas de modo semiartesanal. Um projeto governamental de requalificação dessa feira deveria, portanto, incluir aspectos para além dos estéticos e sanitários. Ver mais profundamente cada experiência singular desses feirantes.

Nessa perspectiva, este capítulo apresenta uma situação específica, como um estudo de caso no interior da FSJ que, ao descrever as tarefas e o trabalho real de uma feirante, lidando cotidianamente com restrições de naturezas diversas em situação de trabalho, evidencia as estratégias adotadas para viabilizar o trabalho e os riscos para a saúde pública e do trabalhador.

\section{Trabalho informal feirante, empreendedorismo e construção de saberes}

A ação ergonômica, enquanto objeto da transformação do trabalho, se dá por meio da interação entre as lógicas do social e da produção. Trata-se portanto de uma abordagem que vislumbra situações de trabalho que não causem danos à saúde dos operadores no exercício de suas competências, seja no plano individual ou coletivo, valorizando suas capacidades, além de proporcionar o alcance dos objetivos econômicos. (GUÉRIN et al., 2001) 
A atividade feirante, em geral, é considerada intensiva, com tecnologias pouco sofisticadas, vínculos de trabalho precários, dirigida às camadas médias e populares da sociedade. (SANTOS, 2004) A feira possui peculiaridades próprias da atividade informal, com distintas formas de produção no campo da compreensão do trabalho feirante. Os conhecimentos da análise ergonômica do trabalho aplicados à atividade feirante podem evidenciar diversas situações de ordem cultural, social, econômica e humana, conforme serão apresentadas neste estudo. A dinâmica da FSJ gera inclusão e exclusão de trabalhadores. Essa dinâmica impõe a esses trabalhadores esforços visando à manutenção do seu comércio, da sua sobrevivência e de sua família.

A FSJ se constituiu em um referencial culturalmente estabelecido para a população mais carente da cidade do Salvador, região metropolitana e Recôncavo Baiano, enquanto local de troca de força de trabalho por alimentos ou pequenas remunerações, ofertadas por pequenos e médios comerciantes. Desse modo, observam-se trabalhadores de distintas camadas sociais, dos mais pobres aos níveis médios de renda e trabalho, conformando um cenário de movimento diário na garantia da sobrevivência. Contudo, na complexidade dessas atividades, também se inscrevem exclusão e estigma, pois, como a FSJ é mais valorizada pelas camadas mais baixas da sociedade, há sempre o receio dos feirantes de que eventuais mudanças neste cenário possam representar ameaças aos seus postos de trabalho diante da percepção de desvalorização com que os setores da economia formal os veem.

Nesse sentido, observa-se que os trabalhadores se especializam e cooperam entre si num claro propósito de pertencimento e identidade do território de produção, tanto individual quanto coletivo. Este movimento pode ser compreendido como autonomia e automobilização do indivíduo, conforme estudo de Zarifian (2001), ao definir competência, iniciativa e responsabilidade diante de situações laborais. Essas, na feira em estudo, foram registradas como estratégias de produção e acordos entre os parceiros.

Nesta perspectiva, vale destacar as negociações com fregueses e fornecedores, a busca por melhor apresentação do produto final, as parcerias com trabalhadores de outras atividades, a compreensão da atividade do outro, enquanto referencial para o melhor desenvolvimento de seu trabalho, dentre tantas abordagens reconhecidas como saber-fazer e saber-ser feirante.

Saber-fazer é concernente ao domínio das ferramentas, ao funcionamento das máquinas, procedimentos ordinários ou extraordinários, respos- 
tas a demandas particulares dos usuários e aos métodos em contextos bem específicos. (ASSUNÇÃO, 2003) Saber-ser recobre o conjunto de comportamentos de adaptação, relações com o outro, os contornos variáveis das demandas apresentadas pelas condições de trabalho flutuantes e a relação com os diferentes usuários e clientes que demandam serviços. (MINET, 1995)

Ambos os saberes se entrecruzam na habilidade em que a cognição ambiental abarca percepção, memória, atitudes e preferências humanas, além de outros fatores psicossociais. Nesse aspecto, os espaços de referências são organizados e decodificados para serem incorporados à memória e às estruturas de representação. (SERPA, 2007) Por esta razão, os pequenos espaços de cada comerciante da FSJ se mantêm, constituindo-se em referências de vizinhança e freguesias.

Característica da atividade informal feirante, a autonomia é, sem dúvida, um dos mais significativos objetos deste estudo, principalmente no que tange à compreensão laboral desenvolvida por eles mesmos: concepção da atividade, execução e cuidado de si. A concepção da atividade aqui analisada não se refere somente ao indubitável poder criativo desses trabalhadores, que em meio às demandas caóticas da informalidade feirante, desenvolvem estratégias de superação e reinventam outras, mas, sobretudo, há uma compreensão do outro, enquanto colaborador do seu desenvolvimento, mesmo diante dos inevitáveis conflitos.

Para a análise da execução da atividade, faz-se necessário ter em conta a noção de gestão e questionar o modo como o trabalhador feirante consegue dar conta de uma heterogeneidade de aspectos relacionados à construção do seu trabalho. Ou seja, como consegue gerenciar as demandas específicas do ofício, que se apresentam em meio à busca dos objetivos da atividade; as interfaces; montante, jusante e laterais; a concepção dos orçamentos e dos tempos, dos indicadores econômicos de desempenho e das relações humanas e sociais. (SCHWARTZ, 2004) Cada detalhe do conjunto de objetos que formam suas atividades são inscrições da cultura da feira, que se apoiam na rotina, na experiência e memória viva de um cotidiano que sempre se renova. Desse modo, cuidam de si, no sentido de minimizarem impactos à saúde.

$\mathrm{O}$ trabalho informal feirante reúne um conjunto de atividades que são desenvolvidas em sua maioria de modo empírico, constituídas a partir da relação com: o ambiente, trabalhadores, sociedade, demandas sociais, cul- 
turais, políticas e econômicas, tanto no âmbito particular quanto no coletivo das representações das atividades.

Para melhor detalhar esse desenvolvimento na FSJ, inspirado no dispositivo de três polos proposto por Schwartz (1999), adota-se aqui um modelo de análise do trabalho informal feirante através de uma abordagem denominada de Redes Co-labor-ativas Inclusivas da Atividade Feirante Informal. Estas redes são constituídas a partir da premissa de que na feira a co-labor-ação é o principal instrumento para conceber, implementar e desenvolver atividades capazes de garantir a sobrevivência dos indivíduos através da preservação dos coletivos.

Observa-se que na FSJ essas redes co-labor-ativas se apresentam de diferentes formas e estágios, mantendo um ciclo orgânico retroalimentado por três bases, a coinclusão, a coeducação e a cooperação. A inclusão de membros da comunidade, as aprendizagens, as relações familiares, comerciais e a cooperação são representações marcantes do cotidiano da FSJ, no que concerne à esfera econômica, cultural, social, política e humana. Desses pressupostos, descreve-se a seguir as observações do caso em estudo.

\section{O trabalho de ralação de mandioca e seu contexto - uma descrição etnográfica}

No interior desta feira, entre as ruelas longas e estreitas, surge uma pequena canaleta por onde escorre a água da limpeza de alguns boxes e da chuva. Bem junto dessa canaleta e sobre um chão escorregadio e recoberto por uma camada fina de lama, encontra-se a máquina de ralar mandioca construída por Balbina. Mantida acorrentada ao lado de uma pequena barraca de $4 \mathrm{~m}^{2}$, esse equipamento de ferro e alumínio, em formato de trapézio, tem na lateral direita superior uma bandeja de entrada e na esquerda um saco transparente acoplado a um balde receptor do produto final: a massa de mandioca. $\mathrm{O}$ principal componente deste equipamento é o cilindro de ralação. Uma peça formada por cerdas pontiagudas de metal que através do processo de rotação acelerada possibilitam a ralação da mandioca.

“Essa máquina é meu pai, minha mãe”, diz Balbina, ao terminar sua demonstração de ralar mandioca na máquina. Depois, lava tudo enquanto conversa sobre sua experiência. Descansa uns dez minutos e reinicia sua tarefa de ralação das raízes da mandioca descascadas, limpas e selecionadas. Estas ficam dispos- 
tas longitudinalmente e enfileiradas sobre a bandeja de entrada da máquina, que, ao ser acionada, dá início ao processo de ralação e produção da massa.

A agilidade demonstrada por Balbina é capaz de impressionar tanto os parceiros de feira, quanto os visitantes, compradores habituais, transeuntes, que não escondem a curiosidade de saber sobre esta atividade de ruído perturbador. Com um olhar atento ao conjunto de tarefas que compõem a ralação, Balbina promove nos espectadores momentos de aflição, ao demonstrar a funcionalidade da máquina ao mesmo tempo em que cumprimenta amigos e negocia com fregueses.

Raiz por raiz, Balbina retoma a tarefa de ralação da mandioca, mesmo evidenciando visíveis sinais de exaustão. Por vezes alonga o corpo, sacode os braços, interrompe a ralação e para. De maneira extraordinariamente envolvida, parece animada e atende aos fregueses. E tudo recomeça outra vez.

Balbina criou essa máquina a partir da junção de um motor para processamento de mandioca e um cilindro ralador, que encomendou na cidade de Santo Antonio de Jesus, no Recôncavo Baiano. Todos os demais itens que compõem o equipamento foram adaptados por ela: a estrutura de ferro, que constitui o esqueleto do instrumento, bem como as madeiras, as folhas de alumínio que revestem a estrutura e a bandeja de entrada.

A construção desse equipamento nasceu a partir da necessidade de produzir a massa da mandioca, de maneira mais rápida e menos desgastante. Produto muito procurado na culinária nordestina, matéria-prima para bolos e outras iguarias, antes produzida manualmente, há muito garante $\mathrm{o}$ seu sustento. "Eu aprendi a desenvolver isso com cara, coragem e força de vontade, porque quem não tem estudo tem que ir à luta, tem que descobrir de onde vaiganhar o pão de cada dia", conta a mulher de quase 60 anos, mãe de duas filhas, enquanto ensaca a massa em pequenos volumes de um quilo.

Ao relatar fragmentos de sua história de vida, relembra que sofreu discriminações durante a juventude. Quando estava só, com uma filha para criar e sem qualquer estudo, teve que trabalhar em várias atividades dentro do ambiente da feira. "Pra mim não tinha tempo ruim, já descarreguei caminhão, vendi montinho, carreguei balaio, fiz de tudo um pouco aqui na feira. Só não aprendi a me prostituir e a roubar, porque isso eu não procurei aprender".

Não se trata de um estudo sobre a compreensão de gênero no trabalho da FSJ, nem mesmo da representação política das mulheres e seus processos em relação aos homens da feira. Mas de uma investigação sobre as condi- 
ções de trabalho de uma mulher e sua experiência de viver como feirante num contexto de dominação masculina. Sobre isso, ela se orgulha de sua inserção na feira onde se sente igual aos homens. E, em seu discurso, observa-se o sentido de força moral em se manter no mundo circundante da feira, no qual se identifica problemas e age de modo prático e objetivo para garantir sua sobrevivência, como aparece em vários momentos deste estudo.

Com o passar do tempo e a soma dos seus esforços, Balbina chegou a ser proprietária de três miniboxes na FSJ, quando vendia flores de artesanato, uma "grande paixão e frustração", pois, não conseguiu sobreviver só com a arte. As somas de diversas dificuldades de ordem familiar e econômica levam a perder tudo o que havia conquistado. A ralação de mandioca representou a retomada da trajetória de Balbina na garantia da sua sobrevivência enquanto feirante e do sustento da sua família, inclusive ressignificando as suas noções comerciais. "Meu fraco é artesanato, mas não tenho tempo, porque artesã faz e tem que esperar o tempo de vender pra poder comer. Eu descobri que na massa, no material pra bolo, todo dia eu vendo".

“Aqui ninguém se importa com a gente”, diz Balbina, referindo-se às condições precárias da FSJ, o descaso do poder público e das autoridades. Em tom de indignação, salienta a insalubridade no ambiente da feira: "Quando chego em casa, lavo meus pés com limão e queimo com álcool. Vocêsabe, que a gente pega as coisas até pelo cheiro", destaca. O seu espaço de trabalho é um lugar negligenciado pelo poder público e todo seu esforço em manter seu pequeno comércio limpo não resulta em salubridade, pois esta depende de estruturas maiores, como saneamento básico e coleta de lixo permanente.

Numa demonstração de cuidado com sua atividade, no que tange ao estabelecimento das relações de afetividade com seus clientes, essa mulher semianalfabeta, e com uma marca de ter sido abandonada aos 12 anos de idade na feira, oferece a todos suas receitas de bolos, além de acolher seus fregueses com calorosas conversas de feira, no qual tudo é história e risos.

\section{A ralação de mandioca: executando as tarefas, constituindo a atividade}

A atividade de ralação mecânica de mandioca é uma das inúmeras na FSJ. A escolha dessa como objeto de análise se deu em virtude do conjunto de elementos que a constituem, do seu caráter inaugural e da representatividade da trabalhadora feirante frente a essa atividade. Inúmeros aspectos e 
peculiaridades desta atividade possibilitam a sua observação sob a luz dos conhecimentos da AET.

Como ponto de partida, algumas questões que se apresentam ao campo da AET norteiam o estudo: como se constrói e se estabelece no trabalho informal feirante esta atividade e, de que forma seria possível promover a redução de danos à saúde da operadora? O trabalho informal feirante, por ter em sua base constitutiva o empirismo, possui a peculiar estrutura de autonomia e, no caso específico desta atividade na FSJ, se encontra à margem de marcos regulatórios. É importante compreender que a relação tarefa, atividade e saúde se estabelece a partir da organização pelos próprios operadores com as inúmeras restrições que exigem a reinvenção todo o tempo.

Alinhado a esse contexto do trabalho, Balbina, em sua prática laboral, remonta sua história de vida. Antes, vale dizer que a busca por construções que sustentam o significado do termo tarefa possibilita compreender as demandas e percepções de impacto à saúde, sentidas por Balbina. As ações abaixo especificadas foram escolhidas por fazerem parte da partitura da ação de ralar mandioca. Os demais produtos comercializados por ela, originais de outros produtores, serão apresentados na tarefa de vendas.

Desse modo, o caso de Balbina mostra que são tomadas como tarefas; a abertura e a preparação do estabelecimento comercial; a compra das raízes; o descasque e a lavagem destas; a ralação da mandioca e a venda dos produtos. Para a execução dessas tarefas nas condições reais, Balbina interage com os diversos fatores que constituem a situação de trabalho, regulando os objetivos e meios disponíveis, lidando com as variabilidades do sistema de trabalho e dos sujeitos em seu entorno para conformar o seu trabalho real ou atividade. A seguir mostram-se os passos dessas tarefas e a constituição da atividade, no cotidiano laboral empreendido por Balbina.

\section{Abertura e preparação do estabelecimento comercial}

Ao chegar à feira, por volta das cinco horas da manhã, Balbina, acompanhada de seu sobrinho que é também seu funcionário, inicia a abertura do seu estabelecimento comercial, retirando lonas, cordas, correntes e cadeados utilizados para a garantia da segurança do equipamento. Baldes de água são carregados para dar início à limpeza do espaço interno da banca, do balcão, da máquina, dos demais instrumentos usados na ralação e da área do entorno. Na sequência, ela efetua a arrumação dos produtos que 
restaram do dia anterior e outros adquiridos para revender como a farinha de puba e a carimã, também derivadas de mandioca.

\section{Compra das raízes}

A compra das raízes é o momento chave, pois diz respeito à escolha da matéria-prima para sua produção. Balbina segue um percurso de aproximadamente quinhentos metros entre sua banca e o fundo da feira, percorrendo um verdadeiro labirinto formado pelos inúmeros becos e passagens no emaranhado da feira. Em seguida, inicia-se a negociação com cada um dos fornecedores de mandioca em seus caminhões. É parte da negociação a vistoria da mercadoria, através da quebra de algumas raízes, e ajuste do preço. Balbina necessariamente passa por todos os fornecedores do dia, em geral, são cinco: “De manhã cedo eu passo, mas não pego logo. Olho o movimento, as mercadorias, se está podre, apreço em um, em outro. Um dia compro num caminhão, um dia no outro, pra eles não botarem banca”.

Sobre essa estratégia, Balbina afirma que em períodos de escassez, os fornecedores tendem a aumentar os valores das mercadorias e que, com a compra sistemática com todos eles, cada dia com um, ela garante menores preços em períodos de crise.

\section{Descasque e lavagem das raízes}

Para o processo de descasque e lavagem das raízes, Balbina conta com o trabalho terceirizado de mulheres que disponibilizam a sua força de trabalho na feira. O número de contratadas varia de acordo com a quantidade de sacos de mandioca a serem descascados. Esta é uma das partes mais críticas do seu negócio, no que diz respeito às demandas psicoafetivas, por conta de o pagamento estar atrelado à quantidade de sacos descascados. Em virtude disso, e da existência de um fluxo maior de venda pela manhã, o que impõe a necessidade de que as raízes sejam descascadas com maior rapidez, Balbina precisa gerir esse processo através da contratação de mais mulheres. Esta ação adotada por ela provoca insatisfação nas mulheres que já executavam a atividade, pois a essas se inflige o imperativo de redimensionamento das suas expectativas de ganho, tendo que repartir as unidades de raízes com as recém-contratadas.

A esse fenômeno, atribui-se a compreensão de que fazendo escolhas engajamos outros trabalhadores, que, por sua vez, remetem a estatutos 
diversos. Por isso, em geral, não há um trabalhador isolado, pois outros estão lá através da preparação do trabalho, da prescrição e da avaliação. (SCHWARTZ; DURRIVE, p. 193, 2007)

\section{A ralação da mandioca - e a centralidade deste saber- fazer de Balbina}

O processo de ralação é iniciado com a troca da água do barril, no qual as raízes descascadas são acondicionadas. O processo de imersão na água possibilita tanto a limpeza das raízes, permitindo a visualização de falhas no descasque, que são corrigidas por Balbina, quanto o amolecimento das mesmas para o seu processamento. Em seguida, as raízes vão sendo colocadas na bandeja de entrada da máquina e inicia-se o procedimento de manuseio da máquina, atividade que demanda da operadora uma carga de atenção, força e destreza. Em simultâneo a tudo isso, Balbina concilia e articula ações de ordem social, administrativa e profissionais.

Uma vez ligada à máquina, o seu motor produz um intenso ruído, que Balbina diz estar acostumada. Ela não usa qualquer equipamento de proteção auricular. Durante a tarefa, que lhe exige agilidade e sincronicidade na disposição das raízes de mandioca na bandeja, são lançadas pequenas porções de massa sobre a sua face, e ainda assim, nenhum tipo de proteção ocular é utilizado por ela. Apenas uma tábua, sustentada por uma das mãos, é usada como escudo. A outra mão alterna entre a retirada de raízes lavadas de dentro do barril e a colocação dessas na bandeja da máquina, pressionando-as para o cilindro. Tudo é rápido e tenso. Toda a atenção é necessária no sentido de evitar a ocorrência de acidentes. Mas o risco é evidente. As cicatrizes de lesões dos seus dedos evidenciam o perigo da atividade.

A observação dos detalhes permite registrar as peculiaridades do método empregado por Balbina. Antes de ligar a máquina, ela verifica o interruptor que fica ao lado do equipamento, na altura da sua cabeça, a limpeza e as posições dos objetos - balde, saco plástico, barril com as raízes mergulhadas em água e bandeja. A segunda fase de ralação é composta por um período prolongado, compreendido entre o acionamento da máquina e o total enchimento do balde com a massa ralada. Após a execução de 20 minutos da tarefa, são perceptíveis os sinais de desconforto e fadiga, provocados pela postura de semiflexão do tronco para empurrar a mandioca contra o cilindro, com uma demanda de força na região paravertebral do dorso. Este es- 
forço é atenuado com o descanso das pernas, por meio de sua alternância em semiflexão do joelho, e da retomada da posição ereta do seu tronco, a cada parada por cerca de dez minutos.

Ao final do processo, braços e mãos ficam recobertos de resíduos de massa processada. Ela retira o excesso de mandioca da tábua e lança sobre a bandeja de entrada das raízes. Recolhe o saco acoplado com a massa ralada e, com um olhar orgulhosamente dadivoso, reafirma: "essa máquina é meu tudo. Deus me abençoou quando eu criei essa gerigonça. Olhe pra aqui, fininha”, diz ela, ao se referir à qualidade da massa. "A melhor da feira”, complementa um freguês.

\section{Venda da massa ralada}

Para o processo de venda da massa, Balbina executa as seguintes tarefas: preparação, exposição do produto e fidelização dos clientes. Na preparação do produto para a venda, ela utiliza a balança da barraca vizinha para pesar a primeira porção da massa, numa fração de um quilo. Esta é a única porção estabelecida com o uso da balança. Todas as demais serão medidas por meio de uma técnica denominada por Balbina como "de olho".

Com relação à promoção do produto, Balbina expõe as massas no balcão de maneira organizada, bem como seus bolos de aipim, carimã e puba. Concomitantemente, também fideliza seus clientes com tratamento personalizado por meio de informações sobre acondicionamento, validade e outros usos da massa como em pudins, biscoitos, mingaus e beijus. Irradia simpatia com conversa sobre sua experiência de viver na feira, criar filhos e seus casos de amor. Principalmente histórias sobre seu marido, morto recentemente, e de quem declara sentir falta. Para um dos clientes que aguarda atendimento, ela diz: “Pega dois quilos de aipim pra meu amigão aqui. No capricho! É três, é? Bota quatro pra ele meu filho”. Tudo é graça no pequeno comércio de Balbina.

\section{Do uso ao cuidado de si}

Outra questão a ser tomada em conta sobre o trabalho informal feirante refere-se ao que Schwartz e Durrive (2007) assinalam concordantes com Guérin e colaboradores (2001), sobre a variabilidade do meio ambiente onde o trabalho ocorre. 
Ele jamais se repete exatamente de um dia para o outro, ou de uma situação de trabalho para outra. Então, aí está uma primeira infidelidade do meio. Cada pessoa vai tentar 'lidar com' as lacunas ou as deficiências a seu modo, pois ela não pode fazê-lo de uma maneira padronizada. Ela o faz com sua história, seus próprios valores. E ao mesmo tempo ela vai contribuir ainda mais para singularizar o meio, para dar uma fonte de variabilidade suplementar. (SCHWARTZ, DURRIVE, 2007, p. 191)

Dada a estrutura da feira livre, com seus informais autônomos criativos e suas infiéis estruturas de trabalho variáveis, por natureza, impõe-se a questão de como, diante deste cenário, ainda ser possível cuidar de si.

Diferentemente dos trabalhadores formais, que têm ações de prevenção e outras garantias ao menos normatizadas. Na feira há uma completa ausência de políticas que reconheçam a importância histórica de suas atividades informais. Sem reconhecimento legal e sem promoção à saúde, esses trabalhadores se consideram "sem direito à nada" na difícil tarefa de se cuidar.

O saber-fazer, desenvolvido no cotidiano do trabalho na feira, evidenciou-se como o recurso mais precioso a assegurar a sobrevivência e o futuro incerto. Em meio à precariedade das condições de trabalho e frente à ausência da proteção e seguridade social, Balbina se prepara para o imponderável.

Sendo ela portadora de diabetes e ao saber que essa doença pode provocar retinopatia e levá-la à cegueira, diz "se algum dia me faltar a visão então eu passo no teste, porque só preciso da mão e do tato para trabalhar na minha máqui$n a$ ". De maneira surpreendente, e implicada com o seu trabalho, ela inicia o mais extraordinário uso de si, com toda a sua dramática existência, apresenta a possibilidade de realização da sua atividade ainda que acometida por uma limitação visual. Numa clara exibição da fusão entre a necessidade do cumprimento da tarefa e a perícia para realizá-la, ela liga o equipamento, em seguida, de olhos cerrados, elabora corporalmente a melhor forma de aproximação do cilindro motorizado, iniciando uma manobra dotada de elevado potencial de risco e capaz de provocar aflição nos espectadores da cena. “Repare, vou fazer essa base aqui oh", diz ela, mostrando o tamanho da raiz em relação à distância do cilindro. Em seguida, durante aproximadamente um minuto e meio, opera a máquina com os olhos fechados. "De olho fechado, eu já sei até quando posso levar a mão e quando eu posso parar”. 
Convergente com essa perspectiva, Balbina apresenta três exemplos particulares e referenciais do seu histórico ocupacional de se cuidar, em meio à sua atividade de trabalhadora feirante informal: cuidar de sobreviver economicamente; cuidar de ser mulher num ambiente masculino; e cuidar de ser operadora da máquina raladora desenvolvida por ela. Sobreviver, para Balbina, significa a base elementar de todo trabalhador feirante. Provocada sobre essa perspectiva, ela relembra a sua última crise financeira:

Com todas as dividas e o acidente do filho do meu marido, eu disse: meu Deus, o que é que eu vou fazer da vida? Aí eu pedi uma "bola" (cilindro ralador que compõe a máquina) a um rapaz de Santo Antônio de Jesus. Eu vou botar um aipim pra ralar aqui, ninguém tem e eu vou fazer sucesso com ele. Daí cheguei na Feira do Pau comprei um motor seminovo por 60,00 "Cruzeiros". O pessoal não sabia como fazer bolo de aipim e eu comecei. Aí nasceu o meu novo processo de sobrevivência.

[...] eles diziam: "oh mulher, isso aqui é trabalho de homem." Aí eu dizia, eu não estou pedindo nada, eu só quero trabalhar, tenho minha filha pra dar comida e não estou pedindo nada. Eles diziam assim: "essa mulher é mulher-homem, bota essa miserável para cima do caminhão pra ela pegar sozinha que ela desiste logo.” Aí eu dizia, tudo bem! Então eles ficavam de formiguinha e eu em cima. Naquela época eu tinha uma força que eu não sei, era carregada por Deus, às vezes eu pegava de dois, sessenta (peso em $\mathrm{kg}$ de cada saco), sessenta, cento e vinte... Aí eu pegava assim. Ejogava nas costas deles, um atrás do outro... Aí na hora de dividir eles queriam me dar merreca... Eu dizia que quem trabalhou mais fui eu, ai era um pau pra quebrar, mas acabava dividindo meio a meio.

Cuidou-se como pôde. Tantas vezes sozinha, outras vezes com seus pares. Sofreu maus tratos, assédios e discriminações. Para ela isso é ser mulher feirante. Hoje, respeitada e cansada, entende que está resguardada. Ninguém a perturba mais. Para isso, teve que ser "valente" e "mulher-homem”. Nunca fraquejar.

\section{Considerações finais}

Este estudo de caso sobre Balbina e sua atividade tenta exemplificar o peculiar, a observação situacional, o trabalho real e a saúde ocupacional do feirante. Nesse contexto, a ralação de mandioca é apenas um item das muitas formas de garantir a vida e o trabalho na FSJ. 
Buscou-se estabelecer relações entre o contexto físico e social e a atividade situada de uma trabalhadora feirante, considerando sua dinâmica própria, a organização temporal e espacial na qual as tarefas eram executadas.

As precárias estruturas para execução do trabalho nesta feira, aliadas às estratégias autônomas de regulação para viabilização da produção, requerem a compreensão do modus operandi do mundo do trabalho feirense, que poderia se abrir e contribuir para o campo da saúde do trabalhador feirante.

Evidenciou-se que intervenções a serem adotadas no mundo do trabalho feirante não podem prescindir a experiência dos sujeitos, o saber prático construído cotidianamente, que modula, na situação real de trabalho, a complexa realidade de sobreviver, produzir e se expor aos fatores de risco.

Nesse domínio, na FSJ, há ainda muito o que se apreender e construir.

\section{Referência}

ASSUNÇÃO, A. A. O saber prático construído pela experiência compensa as deficiências provocadas pelas condições inadequadas de trabalho. Trabalho \& Educação, Belo Horizonte, v. 12, n. 1, p. 35-49, 2003.

BAHIA. Secretaria de Cultura. Instituto do Patrimônio Artístico Cultural da Bahia. Projeto de Requalificação da Feira de São Joaquim, cadastramento 2008. Salvador, 2008.

BOSI, E. Memória e sociedade: lembranças de velhos. 13. ed. São Paulo: Companhia das Letras, 1994 .

CLOT, Y. Clínica do trabalho, clínica do real. São Paulo: UNIFESP, [201-]. Disponível em: <http://www.pqv.unifesp.br/clotClindotrab-tradkslb.pdf >. Acesso em: 25 maio 2012.

FREITAS, M. C. S.; MINAYO, M. C. S.; FONTES, G. A.V. Sobre o campo da alimentação e nutrição na perspectiva das teorias compreensivas. Ciência \& saúde coletiva, Rio de Janeiro, v. 16, n. 1, p. 31-38, jan. 2011.

GEERTZ, C. A interpretação das culturas. Rio de Janeiro: Guanabara Koogan, 1989.

GUÉRIN, F. et al. Compreendendo o trabalho para transformá-lo: a prática da ergonomia. São Paulo: Blücher, 2001.

MINAYO, M. C. S. Ciência, técnica e arte: o desafio da pesquisa social. In: MINAYO, M.C.S. (Org.). Pesquisa social: teoria, método e criatividade. 23. ed. Petrópolis, RJ: Vozes, 2004·p. 9-29. 
MINAYO, M. C. S. O desafio do conhecimento: pesquisa qualitativa em saúde.11. ed. São Paulo: Hucitec, 2008.

MINET, F. L'analyse de l'activité et la formation dês compétences. Paris: Éd. I’Harmattan, 1995 .

PENA, P. G. L.; THÉBAUD-MONY, A. Transformações organizacionais e inovações técnicas em hipermercados na França e no Brasil: a emergência do hipercontrole nos espaços de trabalho e consumo. In: DIEESE; CESIT (Org.). Trabalho e abordagem pluridisciplinar: estudos Brasil, França e Argentina. São Paulo, 1995. p. 69-108.

PIRENNE, H. Economic and Social History of Medieval Europe. New York: A Harvest Book, 1936.

SANTOS, M. O espaço dividido: os dois circuitos da economia urbana dos países subdesenvolvidos. São Paulo: EdUSP, 2004. (Coleção Milton Santos, n. 4).

SCHWARTZ, Y. A comunidade científica ampliada e o regime de produção de saberes. Trabalho \& Educação, Belo Horizonte, n. 7, p. 38-46, jul./dez. 1999.

SCHWARTZ, Y. Trabalho e educação. Presença Pedagógica, Belo Horizonte, v. 7, n. $3^{8, p}$. 5-17, mar./abr. 2001.

SCHWARTZ, Y. Trabalho e gestão: níveis, critérios, instâncias. In:

FIGUEIREDO, M. et al. (Org.) Labirintos do trabalho: interrogações e olhares sobre o trabalho vivo. Rio de Janeiro: DP\&A, 2004.

SCHWARTZ, Y.; DURRIVE, L. (Org.). Trabalho e ergologia: conversas sobre a atividade humana. Niterói, RJ: EdUFF, 2007.

SERPA, A. O espaço público na cidade contemporânea. Salvador: EDUFBA; São Paulo: Contexto, 2007.

SOUZA, E. C. A arte de contar e trocar experiências: reflexões teóricometodológicas sobre história de vida em formação. Educação em Questão, Natal, v. 25, n. 11, p. 22-39, jan./abr. 2006.

SOUZA, M. N. C. A teia da feira: um estudo sobre a feira-livre de São Joaquim, Salvador, Bahia. 2010. 252 f. Dissertação (Mestrado em Ciências Sociais) Faculdade de Filosofia e Ciências Humanas, Universidade Federal da Bahia, Salvador, 2010.

ZARIFIAN, P. Objetivo competência: por uma nova lógica. Tradução de Maria Helena C. V. Trylinski. São Paulo: Atlas, 2001. 